\title{
Measured Peak Equipment Loads in Laboratories
}

This technical bulletin documents measured peak equipment load data from 39 laboratory spaces in nine buildings across five institutions. The purpose of these measurements was to obtain data on the actual peak loads in laboratories, which can be used to rightsize the design of HVAC systems in new laboratories. While any given laboratory may have unique loads and other design considerations, these results may be used as a "sanity check" for design assumptions.

\section{Introduction}

Laboratory equipment such as autoclaves, glass washers, refrigerators, and computers account for a significant portion of the energy use in laboratories. However, because of the general lack of measured equipment load data for laboratories, designers often use estimates based on "nameplate" rated data, or design assumptions from prior projects. Consequently, peak equipment loads are frequently overestimated. This results in oversized HVAC systems, increased initial construction costs, and increased energy use due to inefficiencies at low partload operation.

Labs21 has published a best-practice guide which describes strategies to obtain better estimates of equipment loads and right-size HVAC systems, saving initial construction costs as well as lifecycle energy costs. (Available at: http://www.labs21century.gov/toolkit/bp_guide.htm)

Since the guide was published, Labs21 has obtained additional data on measured equipment loads in various laboratories. The purpose of this technical bulletin is to document these data, which were drawn from a total of 39 different lab spaces in nine different buildings from the following institutions: Duke University, Lawrence Berkeley National Laboratory, University of California Davis, University of California Santa Cruz, and University of Wisconsin Madison.

\section{Measurement Approach}

Clamp-on meters were used to take measurements of equipment electrical loads for each lab space. The measurements were taken when the labs were nominally fully occupied and used. In most cases, measurements were taken over a period of one to four weeks. The measured quantities were one or more of the following:

- Apparent instantaneous power: The product of the voltage and the current at any given instant. The maximum value of this number, divided by the lab area is hereafter referred to as the 'Max Inst. VA/sf'.

- Actual instantaneous power: This is the actual instantaneous power draw, which becomes a thermal load to the space. The maximum value of this number, divided by the lab area is hereafter referred to as 'Max Inst. W/sf'.

- Average interval power: This is obtained by averaging the actual instantaneous power over a time interval, typically 15 minutes. This quantity is typically measured by utility interval meters to determine demand charges. The maximum value of this number, divided by the lab area, is hereafter referred to as 'Max Interval Avg W/sf'.

Max Inst. VA/sf is the key metric for sizing the electrical distribution system, whereas Max Interval Avg W/sf is the key metric for sizing HVAC systems. For a further discussion of sizing, the reader is referred to the Labs21 best practice guide. 


\section{Measurement Data}

Table 1 summarizes the measurement data as well as the area and type for each laboratory. The footnotes provide more information on the measurement approach for each building. The laboratory type was characterized by the measurement personnel, and as such do not necessarily refer to any standard definitions for type.

Table 1: Measured peak equipment loads in various laboratory spaces.

\begin{tabular}{|c|c|c|c|c|c|c|}
\hline $\begin{array}{l}\text { Bldg } \\
\text { ID }\end{array}$ & $\begin{array}{c}\text { Space } \\
\text { ID }\end{array}$ & $\begin{array}{c}\text { Area } \\
\text { (sf) }\end{array}$ & Lab Type & $\begin{array}{c}\text { Max } \\
\text { Interval } \\
\text { Avg W/sf }\end{array}$ & $\begin{array}{l}\text { Max } \\
\text { Inst. } \\
\text { W/sf }\end{array}$ & $\begin{array}{l}\text { Max } \\
\text { Inst. } \\
\text { VA/sf }\end{array}$ \\
\hline \multirow[t]{11}{*}{$A$} & 1 & 850 & Biology & 1.68 & 4.99 & 5.14 \\
\hline & 2 & 307 & Biology & 8.64 & 18.61 & 18.73 \\
\hline & 3 & 833 & Biology & 1.83 & 4.32 & 4.50 \\
\hline & 4 & 308 & Biology & 9.94 & 17.83 & 19.69 \\
\hline & 5 & 831 & Chemistry & 3.13 & 4.97 & 5.45 \\
\hline & 6 & 835 & Chemistry & 3.69 & 7.50 & 8.05 \\
\hline & 7 & 832 & Chemistry & 2.16 & 7.05 & 7.07 \\
\hline & 8 & 828 & Chemistry & 1.77 & 4.13 & 4.35 \\
\hline & 9 & 459 & Equipment & 6.02 & 29.07 & 40.00 \\
\hline & 10 & 306 & Equipment & 16.73 & 30.81 & 32.56 \\
\hline & 11 & 1082 & Isotope & 8.07 & 15.29 & 15.83 \\
\hline \multirow[t]{4}{*}{$B$} & 1 & 1071 & Biology & 4.09 & 6.71 & 7.18 \\
\hline & 2 & 711 & Elec Microscope & 9.33 & 18.21 & 19.33 \\
\hline & 3 & 642 & Env. Rooms & 2.80 & 8.47 & 8.73 \\
\hline & 4 & 646 & Instrument & 2.27 & 5.29 & 5.57 \\
\hline \multirow[t]{5}{*}{$\mathrm{C}$} & 1 & 665 & Biology & 9.00 & $n / a$ & $n / a$ \\
\hline & 2 & 790 & Biology & 6.11 & $n / a$ & $n / a$ \\
\hline & 3 & 665 & Biology & 6.03 & $n / a$ & $n / a$ \\
\hline & 4 & 500 & Equipment & 7.86 & $n / a$ & $n / a$ \\
\hline & 5 & 500 & Equipment & 18.62 & $n / a$ & $n / a$ \\
\hline \multirow[t]{7}{*}{$\bar{D}$} & 1 & 1121 & Biology & 3.22 & 4.19 & 4.40 \\
\hline & 2 & 1121 & Biology & 3.92 & 6.00 & 6.48 \\
\hline & 3 & 1138 & Biology & 3.32 & 3.89 & 4.24 \\
\hline & 4 & 1138 & Biology & 1.85 & 2.26 & 2.52 \\
\hline & 5 & 1139 & Biology & 1.14 & 3.38 & 5.87 \\
\hline & 6 & 1139 & Biology & 2.00 & 2.40 & 7.30 \\
\hline & 7 & 1133 & Biology & 5.87 & 7.34 & 7.89 \\
\hline \multirow[t]{4}{*}{$\mathrm{E}$} & 1 & 562 & Biology & $n / a$ & $n / a$ & 5.64 \\
\hline & 2 & N/A & Biology & $n / a$ & $n / a$ & 5.87 \\
\hline & 3 & $\mathrm{~N} / \mathrm{A}$ & Biology & $n / a$ & $n / a$ & 6.61 \\
\hline & 4 & 1222 & Biology & $n / a$ & $n / a$ & 5.85 \\
\hline \multirow[t]{2}{*}{$F$} & 1 & 2052 & Biology & 9.00 & $n / a$ & $n / a$ \\
\hline & 2 & 5843 & Biology & 3.52 & $n / a$ & $n / a$ \\
\hline$G$ & 1 & 1763 & Nanofab Suite & $n / a$ & $n / a$ & 4.83 \\
\hline \multirow[t]{2}{*}{$\mathrm{H}$} & 1 & 825 & Dry lab & $n / a$ & $n / a$ & 10.91 \\
\hline & 2 & 541 & Dry lab & $n / a$ & $n / a$ & 2.01 \\
\hline \multirow[t]{3}{*}{ I } & 1 & 1152 & Biology & $n / a$ & $n / a$ & 1.66 \\
\hline & 2 & 1190 & Biology & $n / a$ & $n / a$ & 2.66 \\
\hline & 3 & 1049 & Bio Lab Support & $n / a$ & $n / a$ & 7.53 \\
\hline
\end{tabular}


Table 1 Footnotes - measurement approach for each building:

- $\quad$ Buildings A,B,C: Continuous instantaneous measurements; Averaged at 15 minute intervals; Instantaneous measurements are non-coincident sum of three phases.

- $\quad$ Building D: Continuous instantaneous measurements; Averaged at 5 minute intervals.

- $\quad$ Building E: Instantaneous measurements at 30 minute intervals.

- $\quad$ Building F: Continuous instantaneous measurements; Averaged at 15 minute intervals

- $\quad$ Buildings $\mathrm{G}, \mathrm{H}$ : No documentation of measurement approach

- $\quad$ Building I: Instantaneous measurements at 15 minute intervals

\section{Analysis}

\subsection{Maximum Interval Average W/sf for Different Laboratory Types}

Figure 1 shows the maximum interval average $\mathrm{W} / \mathrm{sf}$ in biology labs. The data show a wide range in loads in biology labs, from just over $1 \mathrm{~W} / \mathrm{sf}$ to almost $10 \mathrm{~W} / \mathrm{sf}$. Figure 2 shows the correlation between lab area and the maximum interval average $\mathrm{W} / \mathrm{sf}$ for biology labs. The data suggest that smaller labs tend to have higher equipment load densities - possibly because smaller labs may have more equipment per unit area as well as less diversity in loads due to less total equipment.

Figure 3 shows the maximum interval average $\mathrm{W} / \mathrm{sf}$ in chemistry labs and equipment rooms. All the chemistry labs had less than $4 \mathrm{~W} / \mathrm{sf}$. Loads in equipment rooms, which typically contain shared equipment with little or no bench space, can exceed $15 \mathrm{~W} / \mathrm{sf}$.

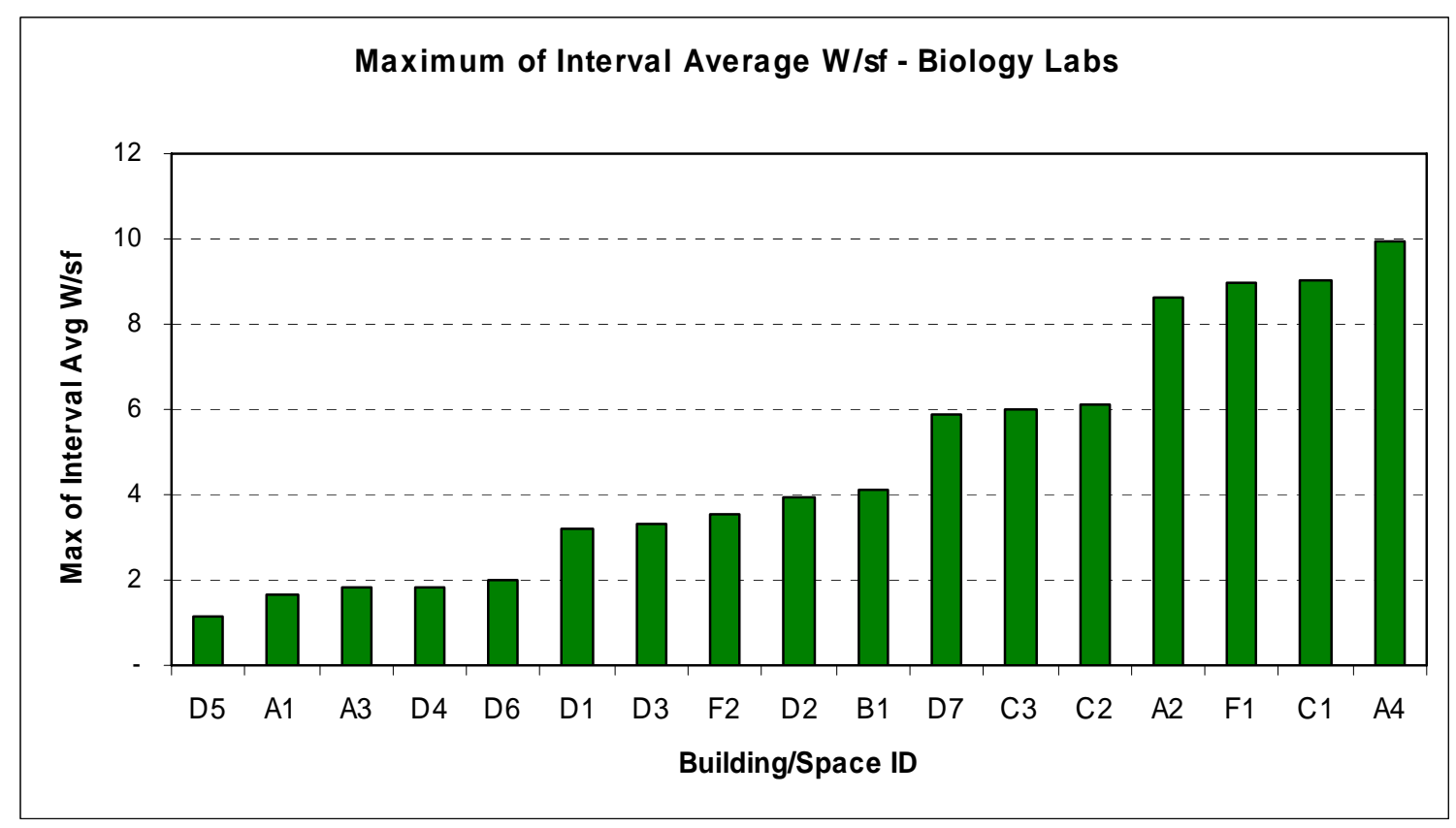

Figure 1 Maximum Interval Average W/sf in biology labs 


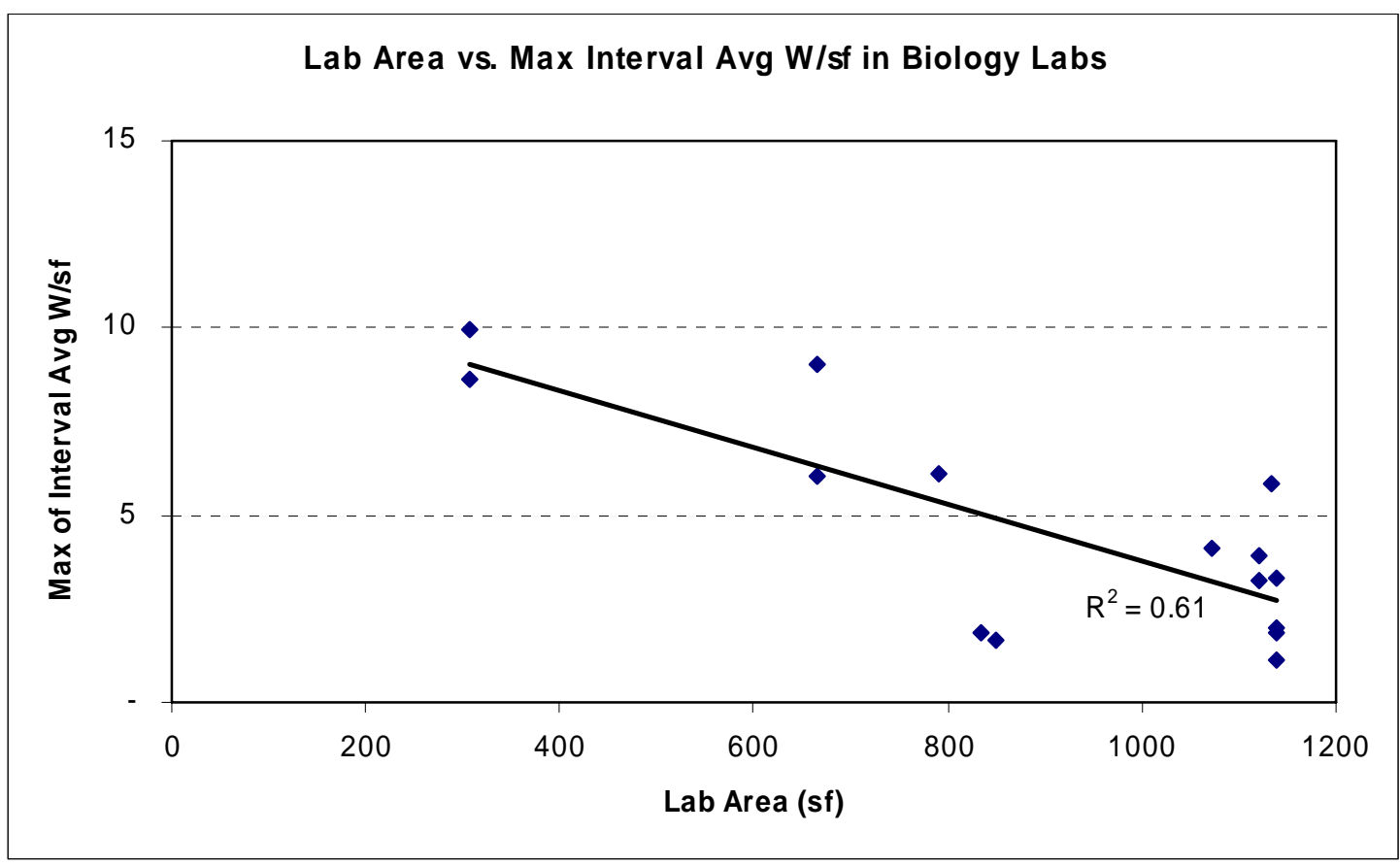

Figure 2 Correlation between lab area and Maximum Interval Average W/sf for biology labs. (Two high lab area outliers removed.)

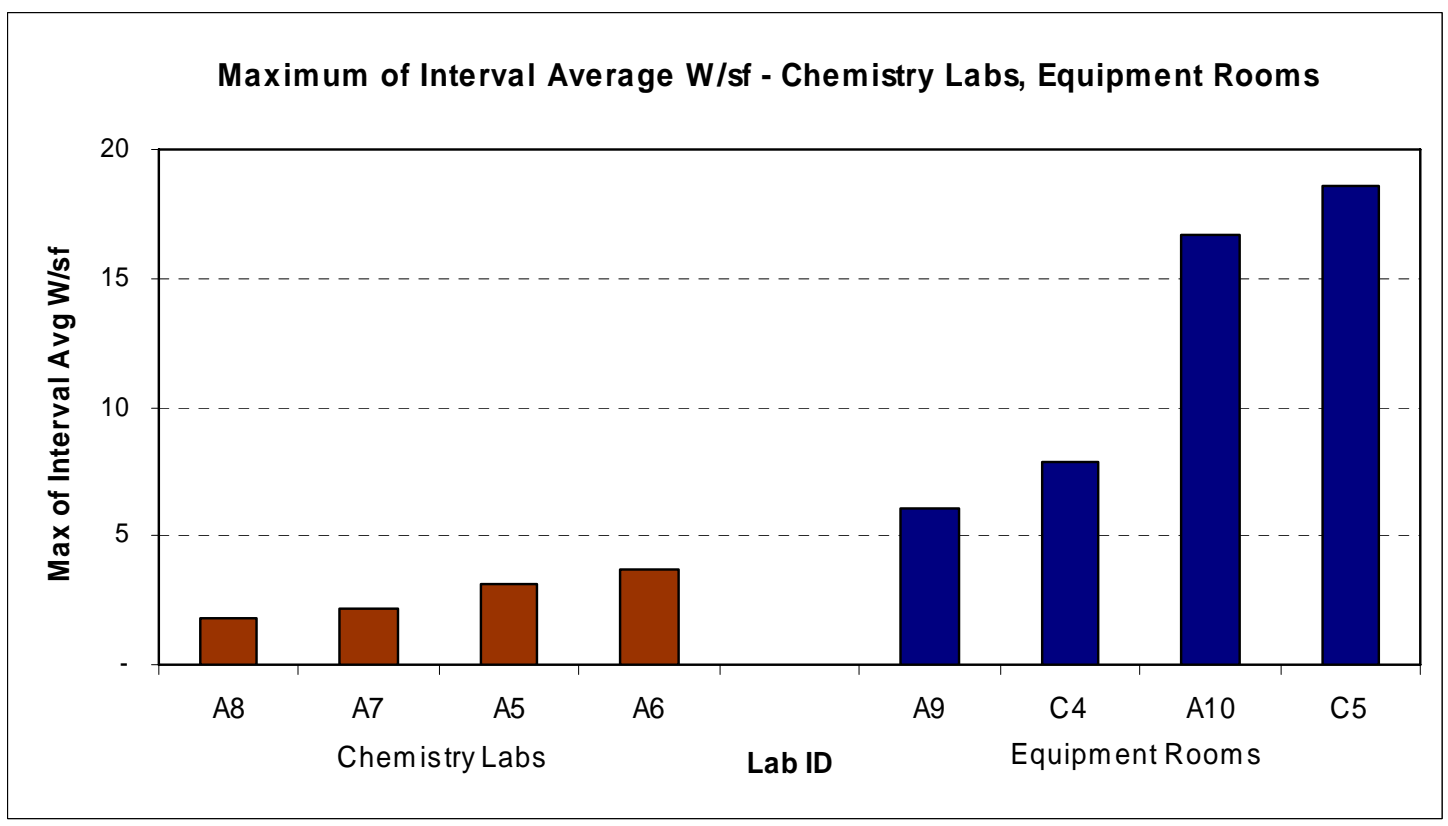

Figure 3 Maximum Interval Average W/sf in chemistry labs and equipment rooms

\subsection{Comparison of Instantaneous and Interval Average loads}

Figure 4 and Figure 5 compare instantaneous loads and interval average loads in Buildings A and $\mathrm{D}$ respectively. The data show that peak interval loads are significantly lower than peak instantaneous loads. This suggests that sizing HVAC systems based on instantaneous loads can result in significant over-sizing. 


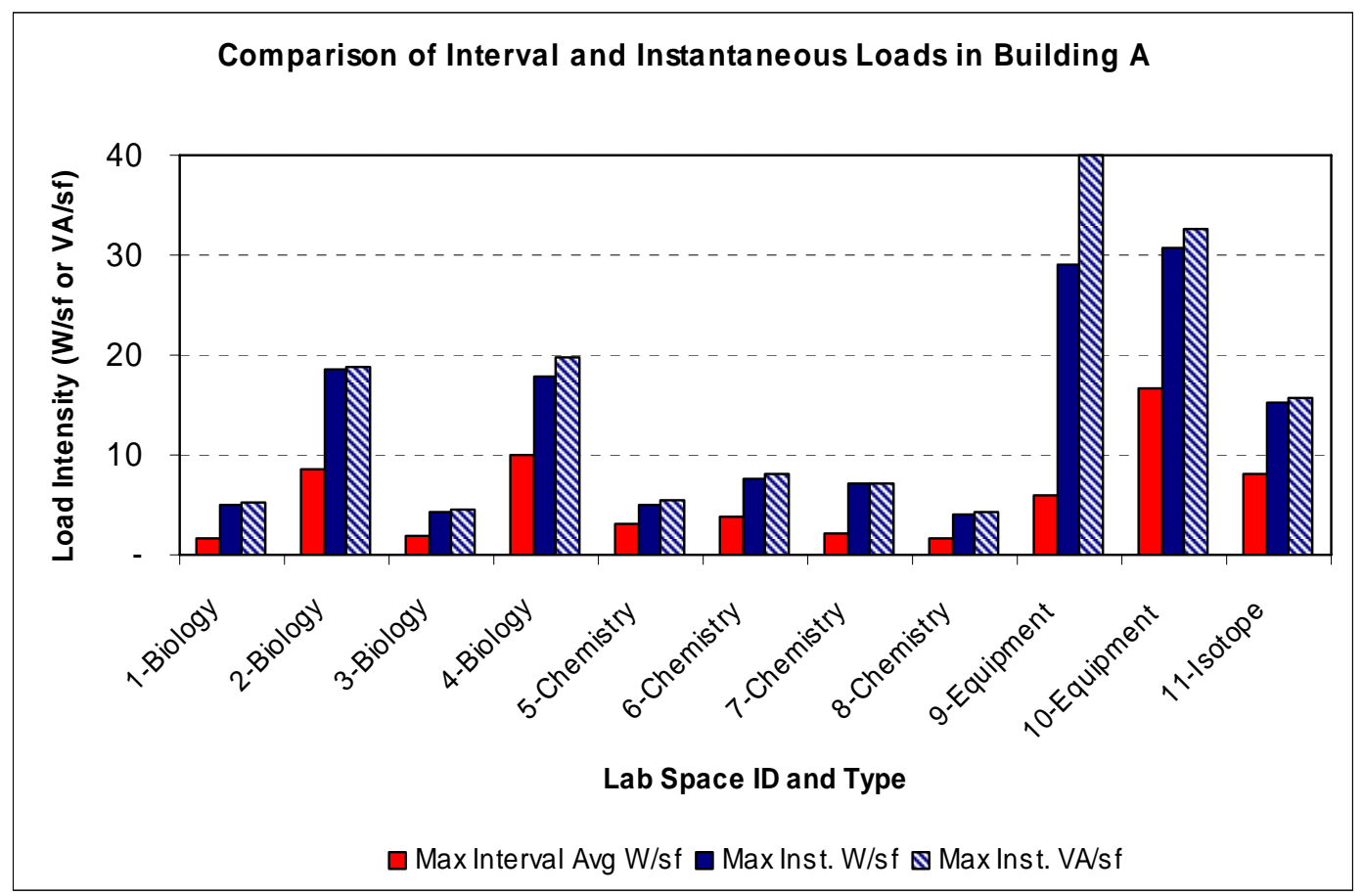

Figure 4 Comparison of instantaneous and interval average loads in lab spaces in Building $A$.

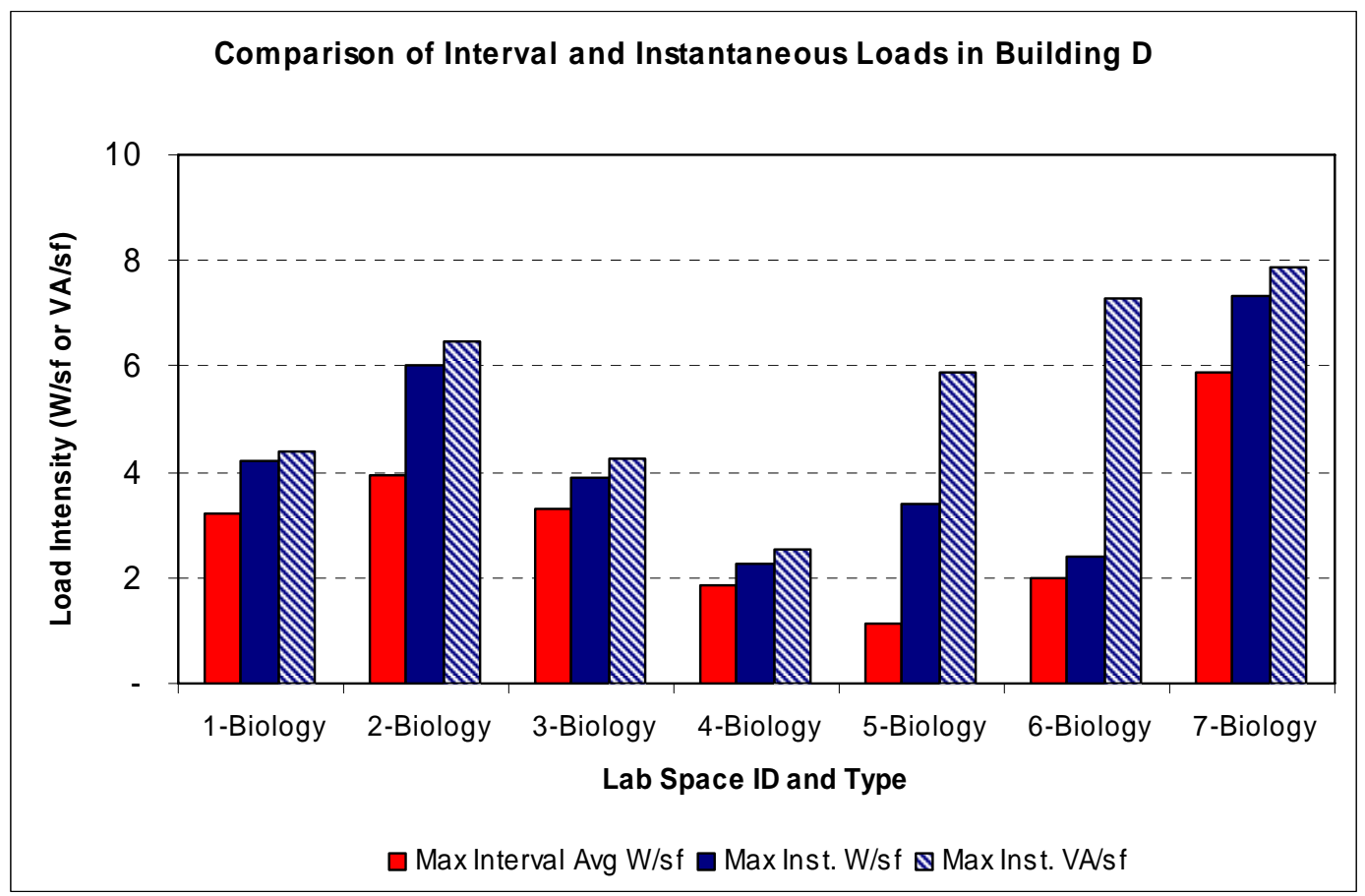

Figure 5 Comparison of instantaneous and interval average loads in lab spaces in Building $\mathbf{D}$.

\section{Conclusion}

This bulletin presented measured equipment load data from various laboratory spaces while they were nominally fully occupied. For HVAC sizing, the key metric of interest is the maximum Interval Average $\mathrm{W} / \mathrm{sf}$. The data for this metric show a wide range in biology labs, from just over 
$1 \mathrm{~W} / \mathrm{sf}$ to almost $10 \mathrm{~W} / \mathrm{sf}$. All the chemistry labs had less than $4 \mathrm{~W} / \mathrm{sf}$. Loads in equipment rooms can exceed $15 \mathrm{~W} / \mathrm{sf}$. These data may be used as a "sanity check" for design assumptions in a new laboratory project. However, laboratories tend to have unique loads and operational characteristics. Therefore, for the new design or major retrofit projects, it is strongly recommended that the measurements be taken in a comparable laboratory that has similar functions and operational characteristics.

\section{References}

Right-sizing Laboratory Equipment Loads, Labs21 Best Practice Guide. Available on the web: http://www.labs21century.gov/toolkit/bp_guide.htm

\section{Acknowledgements}

Measurement data were provided by: William Brewer, Duke University; Steve Greenberg and David Heinzerling, Lawrence Berkeley National Laboratory; William Starr, University of California, Davis; Patrick Testoni, University of California Santa Cruz; Mike Walters, Affiliated Engineers Inc. This bulletin was technically reviewed by Dan Amon, U.S. EPA, and Otto VanGeet, National Renewable Energy Laboratory.

For more information on this bulletin:

Paul Mathew, Ph.D.

Lawrence Berkeley National Laboratory

1 Cyclotron Road, MS 90-3111

Berkeley CA 94720

510-486-5116

PAMathew@lbl.gov

For more information on Laboratories for the 21st Century:

Dan Amon, P.E.

Will Lintner, P.E.

National Energy Manager

U.S. Environmental Protection Agency

1200 Pennsylvania Ave., N.W.

Washington, DC 20460

202-564-7509

amon.dan@epa.gov

Federal Energy Management Program

U.S. Department of Energy

1000 Independence Ave., S.W.

Washington, D.C. 20585-0121

202.586.3120

william.lintner@ee.doe.gov

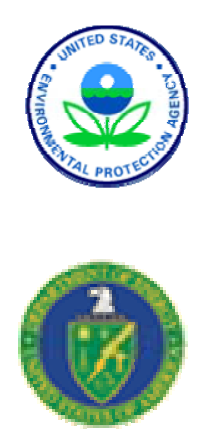

Laboratories for the $21^{\text {st }}$ Century

U.S. Environmental Protection Agency

Office of Administration and Resource Management

www.labs21century.gov

In partnership with the

U.S. Department of Energy

Energy Efficiency and Renewable Energy

Bringing you a prosperous future where energy

Is clean, abundant, reliable, and affordable

www.eere.energy.gov

Prepared at the Lawrence Berkeley National Laboratory

A DOE national laboratory 